\title{
Perfil do empreendedorismo inicial e estabelecido e suas motivações
}

\author{
Profile of initial and established entrepreneurship and its motivations \\ Perfil del emprendimiento inicial y establecido y sus motivaciones
}

Recebido: 18/06/2021 | Revisado: 25/06/2021 | Aceito: 27/06/2021 | Publicado: 12/07/2021

\author{
Tarciara Magley da Fonseca Pereira \\ ORCID: https://orcid.org/0000-0002-7570-8471 \\ Universidade Potiguar, Brasil \\ E-mail: tarciara@ufersa.edu.br \\ César Ricardo Maia de Vasconcelos \\ ORCID: https://orcid.org/0000-0003-0398-5733 \\ Universidade Potiguar, Brasil \\ E-mail:cesarmvasconcelos@gmail.com
}

\begin{abstract}
Resumo
O presente estudo teve como objetivo analisar o perfil do empreendedorismo nos estágios inicial e estabelecido e suas principais motivações iniciais. A metodologia qualitativa, que foi caracterizada pelos dados do Global Entrepreneurship Monitor (GEM 2019). Os resultados mostram que no estágio inicial há uma diferença mínima quanto a gêneros; pessoas mais ativas tem características como idade (entre 25 e 44 anos), escolaridade (ensino superior completo) e renda (superior a seis salários mínimos); e a principal motivação é independia financeira e no trabalho. Enquanto que no estágio estabelecido o gênero masculino se sobressai; pessoas com ensino fundamental incompleto, idade entre 45 e 54 anos e renda superior a seis salários mínimos são os mais ativos; e a principal motivação é fazer a diferença no mundo. Palavras-chave: Empreendedorismo inicial; Empreendedorismo estabelecido; Global entrepreneurship monitor; Motivações.
\end{abstract}

\begin{abstract}
A present study aimed to analyze the profile of entrepreneurship in the initial and established stages and its main initial motivations. The qualitative methodology, which was characterized by data from the Global Entrepreneurship Monitor (GEM 2019). The results show that in the initial stage there is a minimal difference regarding genders; more active people have characteristics such as age (between 25 and 44 years), education (complete higher education) and income (above six minimum wages); and the main motivation is financial and work independence. While in the established stage the male gender stands out; people with incomplete elementary education, aged between 45 and 54 years and income above six minimum wages are the most active; and the main motivation is to make a difference in the world.
\end{abstract}

Keywords: Initial entrepreneurship; Established entrepreneurship; Global entrepreneurship monitor; Motivations.

\section{Resumen}

Este estudio tuvo como objetivo analizar el perfil del emprendimiento en las etapas inicial y establecida y sus principales motivaciones iniciales. La metodología cualitativa, que se caracterizó por datos del Global Entrepreneurship Monitor (GEM 2019). Los resultados muestran que en la etapa inicial hay una mínima diferencia de género; las personas más activas tienen características como edad (entre 25 y 44 años), educación (educación superior completa) e ingresos (más de seis salarios mínimos); y la principal motivación es la independencia económica y laboral. Mientras que en la etapa establecida se destaca el género masculino; las personas con educación primaria incompleta, de entre 45 y 54 años y con ingresos superiores a seis salarios mínimos son las más activas; y la principal motivación es marcar la diferencia en el mundo.

Palabras clave: Emprendimiento inicial; Emprendimiento estabelecido; Monitor de emprendimiento global; Motivaciones.

\section{Introdução}

O empreendedorismo na última década tem por objetivo desafiar pessoas e organizações como forma de melhor atender aos requisitos da gestão e suas relações em geral. (Nakao, Costa Leite e Cunha, 2018). Muito embora a sociedade contemporânea vem se mostrando ao longo dos dias bem mais adepta e com bastante conhecimento sobre empreendedorismo se compararmos aos cenários sociais de antes, no entanto em pontuadas circunstancias a motivação de iniciar um negócio ainda seja receoso para a maioria dos indivíduos. 
O crescimento do empreendedorismo ocorreu após as duas guerras mundiais, devido a centenas de milhares de homens mortos e mutilados. Diante desse cenário, as mulheres tiveram como única alternativa fazerem-se provedoras da casa, assumir o trabalho desses homens e com o passar do tempo e de forma despretensiosa adentraram no mercado de trabalho (Hobsbawn; 2004; Probst, 2005). Portanto, as mulheres, conquistaram a ampliação do seu lugar na sociedade e na economia, e desde então, a crescente participação delas no mundo dos negócios não se deu apenas dentro das empresas já estabelecidas, mas também na aquisição de negócios novos (Franco, 2014). No entanto, existe uma diferença maciça entre os empreendimentos iniciais onde as taxas são altas e estabelecidos onde decai essas taxas.

Nesse contexto, o presente trabalho tem como objeto de estudo os empreendedores brasileiros. O objetivo é analisar o perfil do empreendedorismo inicial e estabelecido e suas motivações iniciais a partir dos dados do Global Entrepreneurship Monitor [GEM] (2019). Quanto aos aspectos metodológicos, constitui-se como uma pesquisa qualitativa. Cabe salientar que o GEM (2019), utilizou como técnica de coleta de dados entrevistas com 2.000 indivíduos com idade adulta entre 18 e 64 anos.

Os resultados mostram que no estágio inicial há uma diferença mínima quanto a gêneros; pessoas mais ativas tem características como idade (entre 25 e 44 anos), escolaridade (ensino superior completo) e renda (superior a seis salários mínimos); entre os menos ativos estão pessoas com o ensino fundamental incompleto e renda entre 1 até 2 salários mínimos e a principal motivação é independia financeira e no trabalho. Enquanto que no estágio estabelecido o gênero masculino se sobressai; pessoas com ensino fundamental incompleto, idade entre 45 e 54 anos e renda superior a seis salários mínimos são os mais ativos; pessoas entre os 18 a 24 anos, ensino médio e superior completo e renda de até 2 salário mínimos são considerados os menos ativos; e a principal motivação é fazer a diferença no mundo.

Espera-se, com esse estudo servir de referência para o campo acadêmico como fonte de informações para futuras pesquisas que investiguem os empreendedores brasileiros, possibilitando analises diversas sobre a proporção e grandeza desses personagens. A contribuição para a praxis foi descrever um panorama de informações sobre empreendedorismo inicial e estabelecido, assim como as principais características de cada etapa e suas motivações de forma simples e atualizada, servindo como radar e instrumento para criação e manutenção de políticas públicas voltadas exclusivamente para o crescimento do empreendedorismo.

\section{Revisão de Literatura}

\subsection{Empreendedorismo breves relatos e conceitos}

A nova conjuntura econômica tem encontrado no empreendedorismo fatores que levam a induzir e desenvolver a economia de regiões e países. Fillion (1999) e Schumpeter (1997) entendem que ao produzir coisas novas ou com formas diferentes criar as mesmas, corresponde a movimentar de maneira diferente esse produto e vontade, levando assim a mudanças e um crescimento possível. Segundo Dornelas (2007) para o sucesso do empreendedor se faz necessário planejar sobre o que se está ofertando e determinar sua viabilidade.

Schumpeter (1997) relata que o empreendedor é imprescindível para a economia, pois é ele quem traz o espírito inovador aos processos, que permite mudanças significativas nos patamares econômico e social, através do que o autor chama de "destruição criativa". Dessa forma, empreendedorismo é a criação de algo nunca visto com e que the seja dado valor, com dedicação, tempo e o esforço necessários, é assumir riscos financeiros, psíquicos e sociais ao mesmo tempo e receber como consequência a recompensa da satisfação e da independência tanto financeira como pessoal (Hisrich, Peters \& Sheper, 2009). Já para Dolabela (2010) é um o processo transformador do sonho que o torna real gera riqueza.

Farber, Hoeltgebaum e Klem (2011) em seu estudo notaram que existem características em relação ao comportamento dos empreendedores e o empreendedorismo tem sido objeto de estudo realizado mundialmente por autores de forte influência 
como Degen (1989), Dolabela (1999), Dornelas (2005), Fillion (1993), Hisrisch e Peters (2004), Kuratko e Hodgetts (1998), McClelland (1972), Rocha (2014), Schumpeter (1997) e Timmons (1985).

Cooley (1990) se colocou como um dos relevantes autores a realizar um modelo que demonstra as competências dos empreendedores. Dessa forma, ele traz dez fatores que representam os empreendedores: estabelecer metas; planejar e monitorar sistematicamente; ser persistente; ser comprometido; obter informações; buscar oportunidades e ter iniciativa; exigir qualidade e eficiência; 8 calcular os riscos; ser persuasivo e manter rede de contatos; ser independente e ter autoconfiança. Algumas características empreendedoras nascem com eles, outras se desenvolvem com o tempo (Ávila, Barros, Madruga \& Júnior 2014).

Drucker (1998) coloca que os empreendedores não causam as mudanças, porém os empreendedores exploram as oportunidades que as mudanças geram. O empreendedor é uma pessoa sonhadora que busca transformação desse sonho na vida real. (Dolabela, 2010). Não existe idade para ser empreendedor (Baggio e Baggio, 2014). Segundo Dornelas (2008) empreendedor é aquele que ao ver uma oportunidade monta um negócio para gerar renda sobre ele, assume e calcula os riscos.

Para Dolabela (2010) para ser empreendedor não basta apenas ter uma bagagem de conhecimentos, mas ter atitude, comportamento, modo de perceber o mundo e si mesmo, é voltar-se para um exercício em que o risco e o potencial de inovar, de perseverar e de convivência com o incerto. Perceber as oportunidades com a respectiva obtenção de lucro, onde se considera os riscos aparentes, são características de empreendedorismo (Fillion, 1999).

Baggio e Baggio (2014) relatam que o empreendedor deve investigar a viabilização financeira das ideias e das oportunidades. Segundo Dornelas (2008) para obtenção do sucesso no empreendimento, o "Plano de Negócios" torna-se crucial. No entanto, estudos mostram que a maioria dos empreendedores iniciais ou nascentes não sabem como construir um plano de negócios e qual a utilidade dessa ferramenta.

\section{2 $O$ ingresso do gênero feminino ao empreendedorismo}

A elevação da industrialização no Brasil adicionada à contingência econômica, em específico, nos últimos decêndios do século XX, bem como transformações relevantes que se sucederam, tanto no modo de produção das organizações quanto na vida das pessoas, possibilitaram o ingresso da mulher no mercado de trabalho (Carrijo \& Ferreira, 2017).

Amorim e Batista (2011) constataram que as mulheres no decorrer da história passam a assumir tarefas que diferem do ambiente familiar e doméstico devido as mudanças na sociedade e que possuem características similares e diversas na sua busca por seu lugar no mercado de trabalho, características estas decorrentes do feminismo e da necessidade de sustentação da sociedade durante as guerras mundiais. Ainda segundo os autores, as mulheres empreendem por necessidade e por desejarem serem autônomas. O resultado é o empreendedorismo feminino que gera renda, crescimento socioeconômico e profissionalismo.

$\mathrm{O}$ ingresso da figura feminina no mercado de trabalho é uma ação que se desenvolve mundialmente o tempo todo e alguns fatos históricos provocaram a elevação dessa trajetória: a Revolução Francesa (1789) foi um grande divisor no que se refere à amplificação dos direitos das mulheres e moderação de sua exploração; a Revolução Industrial, no século XVIII, trouxe uma ampliação na oferta por mão-de-obra que ficou bastante cara, para minimizar os esses custos as indústrias tiveram que empregar mulheres e até crianças (Carrijo \& Ferreira, 2017).

Scopelli, Galli, Louzada, Terence e Cassia (2017) revelaram que as indicações mais importantes que podem ser observadas nessa dinâmica, com a chegada do gênero feminino ao mercado de trabalho que se tornou um marco histórico irreverente e que tem se destacado por suas habilidades, mesmo com suas limitações que as vezes não são observadas pela gestão. Com responsabilidade e comprometimento conseguiram conquistar respeito dos colaboradores e estão estabelecidas em suas funções com maestria própria, seguras e com respostas positiva exercem suas profissões. 


\subsection{Empreendedorismo inicial e estabelecido de acordo com o GEM}

O GEM (2019) é responsável pela coleta de dado sobre empreendedorismo em todo o mundo. A pesquisa é feita com especialistas nacionais onde analisam o contexto dos países para as pessoas que estão a criar negócios. O empreendedorismo para o GEM (2019) é visto em um sentido amplamente avaliado, podem ser imbuídos empreendedores dos mais diversos setores, com negócios formais ou não. Na conceituação GEM, o empreendedorismo é qualquer iniciativa de criar um novo negócio, seja um trabalho autônomo seja ele individual, um novo empreendimento ou a expansão de uma empresa que já existia.

A pesquisa com a população menos jovem traz uma possível análise das características, motivo e ambição dos envolvidos que iniciam um negócio, assim como de suas atitudes em sociedade em ligação ao empreendedorismo. A pesquisa GEM (2019) busca categorizar esses empreendedores conforme o estágio dos negócios que eles estão. Portanto, empreendedores iniciais que são nascentes ou novos e empreendedores estabelecidos.

Segundo o GEM (2019) os empreendedores nascentes se envolvem na estruturação de um empreendimento onde são os donos, porém falta pagar o salário, pró-labores ou outra forma de remuneração aos proprietários. Os novos empreendedores tanto são proprietários como administram um novo empreendimento. Os empreendedores estabelecidos são aqueles que tanto são proprietários quanto administram e tem de um negócio tido como fortalecido e já em consolidação, que paga salário, prólabores ou outras formas de remuneração aos proprietários.

As taxas de empreendedorismo gerais segundo GEM (2019) são feitos os cálculos de acordo com a pesquisa com as pessoas adultas, que são indivíduos entre 18 e 64 anos. As taxas revelam um quadro do chamado empreendedorismo no país no que mede à proporcionalmente indivíduos envolvidos com essas atividades e ao passo do empreendimento que se envolveram e, mostram seus importantes motivos para serem empreendedores.

\subsection{Motivação para empreender}

O pensamento dos empreendedores como pessoas que dão atenção às oportunidades encontra suporte na visão econômica neoclássica (Vale, Corrêa \& Reis, 2014). Corroborando nesse sentido, Kirzner (1979) relata que o empreendedor é aquele que se está sempre em alerta, para descobrindo e explorando oportunidades novas. Esta habilidade de estarem em alerta torna-se o traço mais relevante de tais pessoas. Estes indivíduos chegam sempre primeiro lugar ao reconhecer oportunidades que trazem lucros aos empreendimentos. Conhecem a hora certa de comprar de um lugar especifico e vender em outros em períodos completamente diferentes. Compram matéria prima e vendem produtos processados (Vale, Corrêa \& Reis, 2014).

Nesse mesmo pensamento Woods (2006), relata que Kirzner (1979) foi o primeiro a pensar e articular uma teoria do empreendedor com base na ideia de alerta. No olhar de Kirzner (1979), a qualidade de ficar alerta provocaria e transpareceria, no entanto, motivos pessoais, sonhos e realizações do próprio empreendedor. O comportamento dos empreendedores frequentemente envolvido com a forma Shumpeteriana, se faz sob duas maneiras: Ao reconhecer e explorar as oportunidades (Audretsch, 2012).

Por sua vez Dornelas (2007) salienta que o empreendedorismo por oportunidade quando tem outras fontes de rentáveis além do empreendimento novo. Quando se analisa o mercado brevemente as chances de obtenção de sucesso são maiores, além de ficar atento aos riscos e benefícios provindos desse empreendimento, contribuindo imensamente socialmente quando gera empregos, renda e riqueza com planejamento. Quase sempre estão nos países com maior desenvolvimento (Machado, Silva \& Fernandes, 2019).

Entretanto o empreendedor por necessidade, ainda de acordo com Dornelas (2007), é a pessoa que a única fonte de renda é o empreendimento. Usualmente começa de forma casual, tentando aprender com erros antes cometidos para evitar ir à falência do seu estabelecimento, embora que as vezes é inevitável está situação. Os países em desenvolvimento são os que apresentam em maior quantidade esta motivação (Dornelas, 2007). 
Dornelas, Timmons e Spinelle (2010) somam que a oportunidade pode aparecer a partir de uma tendência e comportamento do consumidor quando procura apor novos produtos. $\mathrm{O}$ empreendedor trabalha lançando as novas alternativas no momento certo, desse modo agregando valor para o consumidor final (Rocha, 2014).

McClelland (1972), afirma que os valores, a motivação humana e o desejo de se autorrealizar é que induz as pessoas a buscarem o empreendedorismo. O motivo principal que impulsiona o ser a se mover, encontra-se na necessidade de conquistar e realizar coisas. Isto é, sonhar em realizar algo de uma melhor maneira, não apenas para ser reconhecido socialmente ou ser prestigiado, mas, pelo sentido intrínseco de necessitar se realizar pessoalmente (McClelland, 1972). A autonomia é parte relevante para quem deseja ser um empreendedor.

Para Baum, Frese, Baron e Katz (2007), os estudos de McClelland (1972) trouxe bastante influencia a toda uma geração que estuda o empreendedorismo. Vários dos seus correspondentes, atualmente ainda tendem a buscarem características pessoais distintivas que impulsionam as pessoas ao empreendedorismo (Vale, Corrêa \& Reis, 2014). De acordo com Schatz (1971), tais indivíduos são fortemente propensos em particular a apresentarem um excelente desempenho em casos onde pessoas esperam avaliação por padrões superiores de desempenhados. São essas as pessoas moldadas para o empreender. Eles sonham com autonomia, serem independentes e terem desafios prudentes.

\section{Metodologia}

O método utilizado para resolver o problema da pesquisa desse trabalho foi a Pesquisa Qualitativa que para Prodanov e Freitas (2013) é a que considera existir uma ligação entre o sujeito e o mundo que não seja necessariamente obrigatória a expressão numérica, pois, não se preocupa com a representação de números. A preocupação da pesquisa qualitativa é em explicar o porquê das circunstancias, com o aprofundamento do conhecimento, em produzir ideia e nova informação, que compreenda e explique a prática das relações sociais, sem quantificar o valor. Portanto, a presente pesquisa se caracteriza como pesquisa qualitativa de caráter exploratório, o qual utilizou de levantamento documental como instrumento para obter as informações.

Quantos aos objetivos, o presente estudo, pode ser classificado como uma pesquisa exploratória, por oferecer ao leitor uma maior intimidade e a possibilidade de aperfeiçoar as ideias, onde traz uma visão global do tema lido que ainda é moderadamente explorado (Colauto \& Beuren 2006; Raupp \& Beuren 2006). Esta proposta metodológica foi validada por Carrijo e Ferreira (2017) em seu estudo sobre o perfil e a motivação do empreendedorismo feminino no Brasil, e por Cacciotti, Hayton, Mitchell e Giazitzoglu (2016) que realizaram uma pesquisa qualitativa e exploratória com a finalidade de analisar e interpretar o medo do fracasso a partir do olhar dos próprios empreendedores.

Quanto aos procedimentos técnicos, a pesquisa exploratória, sempre, utiliza pesquisas bibliográfica, de campo, documental, de laboratório assim como estudo de caso, por causa da sua maior flexibilização (Colauto \& Beuren 2006; Raupp \& Beuren 2006). Nesse sentido, a presente pesquisa utilizará a técnica documental. Como fonte de informações e de coleta dados, a pesquisa foi realizada com base na metodologia do Global Entrepreneurship Monitor (GEM), esta é a mais relevante pesquisa sobre empreendedorismo mundialmente.

Participaram desta pesquisa 55 países em 2019. A pesquisa é realizada pela Global Entrepreneurship Research Association (GERA), lideradas pela London Business School (Londres) e pela Babson College (Boston). A pesquisa é realizada no Brasil de forma anual desde o ano 2000 pelo Instituto Brasileiro da Qualidade e Produtividade (IBQP), com o apoio do Serviço Brasileiro de Apoio às Micro e Pequenas Empresas (SEBRAE). Em 2019 foram entrevistadas 2.000 pessoas (entre 18 e 64 anos). 


\section{Resultados e Discussão}

\subsection{Empreendedorismo segundo o estágio}

De acordo com uma pesquisa realizada pelo GEM (2019), as taxas de Empreendedorismo inicial (TEA), estabelecido e total inserem o Brasil em uma posição de destaque dentre os 55 países que participaram desse levantamento. O Brasil apresenta a $4^{\mathrm{a}}$ maior Taxa de Empreendedorismo Inicial, ou seja, negócios de até 3,5 anos de existência (TEA=23,3\%). Esse percentual é superior aos índices já registrados, como por exemplo, aos países do BRICS (EUA, Colômbia, México e Alemanha) conforme apresenta a Tabela 1 .

A taxa de empreendedores estabelecidos (TEE), que se caracterizam como negócios com mais de 3,5 anos de existência, o Brasil ocupa a $2^{\mathrm{a}}$ maior taxa $(\mathrm{TEE}=16,2 \%)$ entre os 55 países que compõem a pesquisa, superior aos EUA, Colômbia, México e Alemanha (SEBRAE, 2020). A pesquisa também a posição de liderança do Brasil entre estes países. Tal característica semelhante é a taxa total de empreendedorismo (TTE), onde o Brasil apresenta a $4^{\mathrm{a}}$ melhor marca mundial (TTE=38,7\%) e a maior taxa entre os países do BRICS.

Assim, é possível compreender que a forma como o indivíduo empreendedor pensa e age, será capaz de nortear possíveis ações que objetivem criar, sobretudo em países emergentes, a discussão, espaços, atores sociais e organizações a cultura empreendedora, com vistas ao crescimento socioeconômico, relações de competitividade e desenvolvimento humano (Schaefer \& Minello, 2019).

Tabela 1. $\operatorname{Taxas}^{1}(\mathrm{em} \%)$ e estimativas ${ }^{2}$ (em unidades) de empreendedorismo segundo o estágio e potenciais empreendedores ${ }^{3}$ Brasil - 2018:2019.

\begin{tabular}{lrrrr}
\hline & \multicolumn{2}{c}{ Taxas } & \multicolumn{2}{c}{ Estimativas } \\
\cline { 2 - 5 } & 2018 & 2019 & 2018 & 2019 \\
\hline Empreendedorismo total & 38 & 38,7 & 51.972 .100 & 53.437 .971 \\
Empreendedorismo Inicial & 17,9 & 23,3 & 24.456 .016 & 32.177 .117 \\
Novos & 16,4 & 15,8 & 22.473 .982 & 21.880 .835 \\
Nascentes & 1,7 & 8,1 & 2.264 .472 & 11.120 .000 \\
Empreendedorismo estabelecido & 20,2 & 16,2 & 27.697 .118 & 22.323 .036 \\
Empreendedorismo potencial & 26 & 30,2 & 22.092 .889 & 25.545 .666 \\
\hline
\end{tabular}

Nota. Adaptado de Global Entrepreneurship Monitor - GEM. (2019) Empreendedorismo no Brasil: Relatório executivo. Curitiba: IBQP.

${ }^{1}$ Percentual da população de 18 a 64 anos. A soma das taxas parciais pode ser diferente da taxa total, uma vez que empreendedores com mais de um empreendimento serão contabilizados mais de uma vez.

${ }^{2}$ Estimativas calculadas a partir de dados da população brasileira de 18 a 64 anos para o Brasil em 2018: 136,8 milhões e 2019: 138,1 milhões.

Conforme Tabela 1, o aumento significativo na taxa de empreendedores iniciais está estreitamente ligado ao aumento na taxa de empreendedores nascentes em relação ao ano de 2018, de 6,4 pontos percentuais. Tal fato para explicar o crescimento se deve ao momento social e econômico do país, no qual é possível observar, por um lado, a retomada da economia e a impulsão que houve no meio empresarial e financeiro e, por outro, uma pequena redução nas taxas de desemprego, mantendo ainda muitas incertezas sobre as opções de ocupação e de obtenção de renda para a população. O percentual de empreendedores novos registrou uma pequena redução (0,6 ponto percentual) se comparado ao ano anterior (GEM, 2019).

A Tabela 1 ainda apresenta que a redução na taxa de empreendedores estabelecidos de 4,0 pontos percentuais serve de alerta para os anos seguintes. Baseado nas pesquisas, a redução dessa taxa estaria associada ao número de desistências de parte dos empreendedores desse grupo. Em 2019, é possível observar a disparidade nas taxas dos dois estágios (7,1 pontos percentuais), sendo que a TEA alcançou o seu maior percentual (23,3\%) e a TEE a menor taxa, retornando aos valores obtidos nos anos de 
2016 e 2017 de empreendedores já estabelecidos, em razão das dificuldades enfrentadas nos últimos meses da crise econômica (GEM, 2019).

Para finalizar o cenário acerca das principais taxas do empreendedorismo no Brasil, é imprescindível mencionar a taxa de empreendedorismo potencial (30,2\%), significando que, a cada 10 brasileiros que não são se envolvem em qualquer tipo de atividade empreendedora, três deles apresentam o interesse de investir em um negócio próprio nos próximos três anos. A expectativa é de que, em média serão 8 milhões de novos empreendedores adentrando no mundo dos negócios. Tais números demonstram que é significativo e relevante que se criem políticas, ações e projetos voltados ao empreendedorismo para que sejam cada vez mais abrangentes e dinâmicos os inúmeros modelos relacionados à temática.

\subsection{Perfil dos Empreendedores iniciais e estabelecidos}

Os dados apresentados na Tabela 2 revelam que no Brasil, com relação ao gênero, homens e mulheres mostram proporções equilibradas no que se refere ao empreendedorismo inicial GEM (2019). As taxas apresentadas mostram que $23,1 \%$ das mulheres englobam empreendimentos em estágio inicial e 23,5\% dos homens. A diferença entre os gêneros aumenta quando são verificadas as taxas especificamente de empreendedorismo estabelecido. Essas taxas chegaram a 18,4\% entre os homens e 13,9\% entre as mulheres. Dessa forma, uma minúscula diferença que era de apenas 0,4\%, aumentou para 4,5\% nos empreendimentos estabelecidos (TEE). Explicando simplificadamente, é estimado que exista aproximadamente 3 milhões de pessoas de sexo masculino a mais empreendendo nesta etapa. 


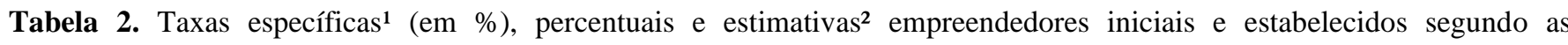
características sociodemográficas - Brasil - 2019.

\begin{tabular}{|c|c|c|c|c|c|c|}
\hline \multirow{3}{*}{$\begin{array}{l}\text { Características } \\
\text { sociodemográficas }\end{array}$} & \multicolumn{3}{|l|}{ Iniciais } & \multicolumn{3}{|c|}{ Estabelecidos } \\
\hline & \multirow{2}{*}{$\begin{array}{l}\text { TEA } \\
23,3 \%\end{array}$} & \multicolumn{2}{|c|}{$\begin{array}{l}\text { Estimativa do número } \\
\text { de Empreendedores }\end{array}$} & \multirow{2}{*}{$\begin{array}{l}\text { TEE } \\
16,2 \%\end{array}$} & \multicolumn{2}{|c|}{$\begin{array}{l}\text { Estimativa do número de } \\
\text { Empreendedores }\end{array}$} \\
\hline & & $\begin{array}{l}\mathrm{N}^{\circ}(\mathrm{Em} \\
\text { milhões })\end{array}$ & $\%$ & & $\begin{array}{l}\mathrm{N}^{\mathrm{o}}(\mathrm{Em} \\
\text { milhões })\end{array}$ & $\%$ \\
\hline \multicolumn{7}{|l|}{ Gênero } \\
\hline Masculino & 23,5 & 16,1 & 50 & 18,4 & 12,6 & 56,5 \\
\hline \multirow[t]{2}{*}{ Feminino } & 23,1 & 16,1 & 50 & 13,9 & 9,7 & 43,5 \\
\hline & Total & 32,2 & 100 & Total & 22,3 & 100 \\
\hline \multicolumn{7}{|l|}{ Faixa Etária } \\
\hline 18 a 24 anos & 24,3 & 6,2 & 19,3 & 7,2 & 1,8 & 8,2 \\
\hline 25 a 34 anos & 26,1 & 8,9 & 27,7 & 12,7 & 4,3 & 19,4 \\
\hline 35 a 44 anos & 26,7 & 8,7 & 27,1 & 18,2 & 5,9 & 26,5 \\
\hline 45 a 54 anos & 22,6 & 5,8 & 18,2 & 23,8 & 6,1 & 27,5 \\
\hline \multirow[t]{2}{*}{55 a 64 anos } & 12,4 & 2,5 & 7,7 & 20,5 & 4,1 & 18,4 \\
\hline & Total & 32,2 & 100 & Total & 22,3 & 100 \\
\hline \multicolumn{7}{|l|}{ Escolaridade $^{1}$} \\
\hline Fundamental incompleto & 18,4 & 5,5 & 17,2 & 23,2 & 7 & 31,3 \\
\hline Fundamental completo & 23,3 & 6,8 & 21 & 20,2 & 5,9 & 26,2 \\
\hline Médio completo & 24,4 & 14,9 & 46,2 & 12 & 7,3 & 32,7 \\
\hline \multirow[t]{2}{*}{$\begin{array}{l}\text { Superior completo ou } \\
\text { maior }\end{array}$} & 27,6 & 5 & 15,6 & 12,1 & 2,2 & 9,7 \\
\hline & Total & 32,2 & 100 & Total & 22,3 & 100 \\
\hline \multicolumn{7}{|l|}{ Renda familiar } \\
\hline Até 1 salário mínimo & 23,4 & 5,5 & 17,2 & 13,5 & 3,3 & 14,7 \\
\hline $\begin{array}{l}\text { Mais de } 1 \text { até } 2 \text { salários } \\
\text { mínimos }\end{array}$ & 20,6 & 8,4 & 26 & 13,4 & 5,6 & 24,9 \\
\hline $\begin{array}{l}\text { Mais de } 2 \text { até } 3 \text { salários } \\
\text { mínimos }\end{array}$ & 22 & 6,1 & 18,8 & 17,2 & 4,8 & 21,6 \\
\hline $\begin{array}{l}\text { Mais de } 3 \text { até } 6 \text { salários } \\
\text { mínimos }\end{array}$ & 27,1 & 8,6 & 26,8 & 18 & 5,8 & 26,2 \\
\hline \multirow[t]{2}{*}{$\begin{array}{l}\text { Mais de } 6 \text { salários } \\
\text { mínimos }\end{array}$} & 31,8 & 3,6 & 11,1 & 24,6 & 2,8 & 12,7 \\
\hline & Total & 32,2 & 100 & Total & 22,3 & 100 \\
\hline
\end{tabular}

Nota. Adaptado de Global Entrepreneurship Monitor - GEM. (2019) Empreendedorismo no Brasil: Relatório executivo. Curitiba: IBQP adaptada pelos autores

${ }^{1}$ Percentual da população referente a cada categoria da população (ex. 24,3\% da população de 18 a 24 anos no Brasil são empreendedores iniciais).

${ }^{2}$ Estimativas calculadas a partir de dados da população brasileira de 18 a 64 anos para o Brasil em 2019: 138,1 milhões.

Contudo, o GEM (2019) relata que no empreendedorismo inicial necessariamente não existe quase diferença entre homem e mulher. Esse quadro permanece em constante harmonia em nuance ao empreendedorismo brasileiro por volta dos anos e uma taxa maior de empreendedores do público masculino que possuem negócios já consolidados. Nessa perspectiva, Bertolami, 
Artes, Gonçalves, Hashimoto e Lazzarini (2018), afirmam que os resultados sugerem a adoção de práticas gerenciais e critérios que envolvam o comportamento do empreendedor como fator que favorece a sobrevivência da empresa. Sobre isso, foi ainda identificado que as mulheres que atuam como empreendedoras enfrentam mais barreiras para constituir seus negócios do que os homens.

Esse dinamismo se deve, talvez, aos seguintes fatos: em primeiro lugar culturalmente, a presença predominante de homens nas atividades empreendedoras pode ter contribuído na geração de negócios estabelecidos, de uma maneira mais forte. Por outro lado, a inserção da mulher no empreendedorismo, assim como vem ocupando outras áreas no mercado de trabalho, vem crescendo ao longo dos anos, porém, as mulheres ainda possuem uma tímida atuação nos negócios já estabelecidos. Todavia, Silva e Silva (2019) apresentam resultados de que no Brasil, entre os anos de 2002 a 2016, houve sim um avanço da contribuição das mulheres na economia.

Em segundo lugar, quando se trata da passagem dos empreendedores iniciais para os empreendedores estabelecidos, há um número maior de abandono do negócio por parte das mulheres do que pelos homens. Tal fato pode ser explicado pelos seguintes fatores: o público feminino possui negócios que podem enfrentar maiores desafios e obstáculos; tipo de motivação para abrir um negócio, que no caso das mulheres seria por necessidade, apresentando um percentual maior do que dos homens. Por essa razão, é possível depreender que parte das mulheres encontra no empreendedorismo um meio de renda em momentos de crise, mas que abandona o negócio quando há melhora no orçamento familiar; e, outros aspectos culturais, como o maior envolvimento das mulheres nas atividades domésticas do que nas empreendedoras (GEM, 2019). Mesmo assim, a mulher brasileira com seu jeito individual de ser gestora, cada dia consolida e invade o mercado de trabalho como empreendedora e, atualmente, representam a grande maioria dos novos empreendimentos do país, corroborando dessa forma a sua relevância no espaço da economia nacional (Carrijo \& Ferreira, 2017).

No tocante à idade, em 2019, aqui no Brasil, de todas as faixas etárias consideradas, a que se encontra na faixa de 55 a 64 anos, é a que mais se diferencia das demais quanto ao empreendedorismo inicial. Aqui, encontra-se a menor taxa, apresentando um percentual de apenas $12,4 \%$ dos brasileiros envolvidos com algum tipo de empreendimento que esteja no estágio inicial. Nas outras faixas etárias, o percentual varia de 22,6\%, na faixa dos 45 aos 54 anos, até $26,7 \%$ na faixa de 35 a 44 anos. Vale salientar que, mesmo apresentando a menor taxa, o número de pessoas com mais de 55 anos que está iniciando algum tipo de negócio é de aproximadamente 2,5 milhões. E, mais uma vez, esse resultado se sobressai, apresentando de certa forma, uma urgência em compreender os motivos para esse percentual, e pensar em ações de apoio para que esses novos negócios alcancem seus objetivos de modo positivo.

Para o empreendedorismo estabelecido, os brasileiros na faixa etária de 45 a 54 anos são os mais ativos. A maioria dessas pessoas já são proprietários do negócio e gerenciam empresas já consolidadas no mercado. Para esse grupo, a menor faixa etária encontra-se entre os mais jovens, dos18 aos 24 anos, com percentual de 7,2\%. Ainda sendo o menor percentual, esse número significa 1,8 milhões de pessoas que começaram a empreender mais cedo e conseguiram manter seus negócios por mais de 3,5 anos. Os números apresentam uma reflexão sobre os motivos e impactos em começar a empreender desde tão cedo e quais as ações devem ser tomadas para suprir as necessidades em se aperfeiçoar profissionalmente e a buscar conhecimento, com vistas ao pleno desenvolvimento do negócio no futuro.

No que se refere ao nível de escolaridade, observa-se que, no Brasil, em 2019, considerando os quatro níveis de escolaridades, os mais ativos em atividades empreendedoras iniciais são os que possuem o ensino superior completo, apresentando um percentual de 27,6\%. A menor taxa apresentada com um percentual de 18,4\% é verificada no nível dos que não chegaram a completar o ensino fundamental. Porém, ainda que essa seja a taxa mais baixa, esse último nível representa cerca de 5,5 milhões de pessoas, ou seja, 500 mil a mais do que o grupo dos empreendedores iniciais com educação superior completa. 
Quanto aos empreendedores já estabelecidos, as maiores taxas são registradas entre aqueles que não possuem o ensino médio completo, ou seja, $23,2 \%$ e 20,2\% para os que têm o ensino fundamental incompleto e completo, respectivamente. Para aqueles que já possuem o ensino médio ou superior completo, $12 \%$ desses já são empreendedores estabelecidos. No grupo que pertence aos empreendedores estabelecidos com nível de escolaridade inferior ao ensino médio completo representam cerca de 13 milhões de pessoas. Para as pessoas que possuem o nível superior o número é de 2,2 milhões de pessoas.

Em relação à escolaridade, Junior e Sato (2019) afirmam que a educação empreendedora no nível básico está intimamente ligada com a identificação de oportunidades de negócios, diferente do que apresenta a educação empreendedora no nível superior. Tal fato demonstra a importância em se realizar investimentos no ensino e transmissão de conhecimento sobre a temática de empreendedorismo desde os níveis iniciais do ensino, para que seja possível inserir a cultura empreendedora por meio da educação.

Diante desse contexto, Arenhardt (2019), demonstrou que a educação em empreendedorismo é mais eficaz quando aplicada ao desenvolvimento de atitudes, percepção, controle e comportamento. Os autores Silva Melo e Jesus (2018) constataram que $48,57 \%$ das mulheres que empreendem possuem nível superior completo, corroborando com os dados apresentados pelo IBGE e o SEBRAE, que demonstram o crescimento do nível educacional das mulheres empreendedoras.

No que se refere à renda familiar, a pesquisa GEM Brasil 2019 demonstra que, para população que possui até 3 salários mínimos, o envolvimento com atividades empreendedoras em estágio inicial não apresenta grandes diferenças. Nas três faixas de menor renda, o percentual varia de 20,6\%, para renda familiar de 1 até 2 salários mínimos, até 23,4\%, para os que recebem até 1 salário mínimo. Se forem consideradas apenas essas duas faixas de renda, ou seja, até 2 salários mínimos, tem-se um número de 14 milhões de pessoas que estão em atividades que se relacionam com o surgimento de novos negócios.

O maior nível de atividade empreendedora inicial é registrado entre os que auferem mais de 6 salários mínimos como renda familiar. Para este grupo, a taxa é de 31,8\%, com aproximadamente 3,6 milhões de empreendedores, isto é, um número de quase três vezes menor do que os empreendedores inicial cuja renda familiar é de até 2 salários mínimos. Esse resultado demonstra o nível de desigualdade de renda no país, em que um grande número de pessoas recebe pouco, enquanto uma pequena parte recebe muito.

Quanto aos negócios que já apresentam um negócio consolidado há mais tempo, percebe-se que nas duas faixas de renda mais baixas estão também às menores taxas de empreendedores estabelecidos. No grupo de famílias que recebem até dois salários mínimos como renda familiar, a taxa é de aproximadamente 13,5\%. Para aqueles que possuem renda familiar entre dois até seis salários mínimos, a taxa sobe para cerca de 4 pontos percentuais. E, entre os que pertencem a núcleos familiares cuja renda é superior a seis salários mínimos, 24,6\% desses são empreendedores estabelecidos. Para o grupo de empreendedorismo total, nessa mesma faixa de renda apresentada, mais de 56\% das pessoas são empreendedoras, um número de mais de 10 pontos percentuais em relação a todas as demais faixas de renda.

\subsection{Motivações para iniciar um novo negócio}

A pesquisa GEM (2019), inovou na avaliação sobre a motivação para o início de um negócio novo. Onde havia as categorias "por necessidade" e "por oportunidade", a pesquisa considerou novas possíveis motivações. Quatro afirmações foram apresentadas a todos os empreendedores, dessa forma eles se encontraram positivamente ou negativamente relacionados a elas. A abordagem anterior de empreendedorismo por necessidade ou oportunidade, fica expressa que o motivo "ganhar a vida porque os empregos são escassos" exprime o mesmo fato de empreender por necessidade. Dessa forma, possibilita comparar os resultados do ano passado com a nova metodologia do empreendedorismo por necessidade.

De acordo com o GEM (2019), um total de 88,4\% dos empreendedores iniciais concorda que a falta de emprego revela ser um dos fatores para se envolverem e iniciarem o empreendedorismo. Desse mesmo modo, $51,4 \%$ destes apontaram que 
querem fazer parte de um mundo diferente, levando-os a empreender. Em oposição, 36,9\% dos empreendedores confirmam que tem ambições de construírem riqueza ou terem altas rendas, está presente no fator dos motivos que os levaram a iniciar um novo empreendimento. Por último, o percentual de 26,6\% dos empreendedores está nesse ramo de atuação ou se envolvendo em algum tipo de negócio para dar continuidade ao nome da família, explicando assim, que o comportamento das famílias em relação ao empreendedorismo exerce influência significativa, ainda que seja direta ou indireta na tomada de decisão do futuro dessas pessoas (SEBRAE, 2020).

Em sua pesquisa Dutra et al. (2009) constataram que a principal razão para a abertura do negócio foi o desejo de ter a própria empresa, seguido da identificação de oportunidade no mercado. Neves e Amarante (2020) tiveram como resultados iniciais o desejo de ser empreendedor e a sonho de ser e gerar a mudança na vida dos indivíduos e em sua vida. No mundo em curso, onde se caracteriza de uma forma de desemprego estruturado, nota-se, deforma crescente, a presença, também presente, de um tipo de empreendedor que se move, não obrigatoriamente por oportunidade, e, sim, pela necessidade de sobreviver (Vale, Corrêa \& Reis, 2014). Dessa forma cabe a cada empreendedor um motivo, uma realidade, uma atitude, um sonho a ser realizado.

\subsection{Perfil do empreendedorismo inicial e estabelecido e suas motivações iniciais}

Perfil do empreendedor em estágio inicial: Diferença mínima entre o gênero feminino e masculino. A pessoas com 25 a 44 anos de idade são os mais ativos. Encontram-se na faixa de 55 a 64 anos os menos ativos. Os indivíduos com o ensino superior completo são os mais ativos. As pessoas com o ensino fundamental incompleto são os menos ativos. As pessoas que estão na faixa de renda superior a 6 salários mínimos são as mais ativas. Os menos ativos estão na faixa de renda entre 1 até 2 salários mínimos. Motivações dos empreendedores inicias: Em primeiro lugar, "Para ganhar a vida porque os empregos estão “escassos"

Perfil do empreendedor em estágio estabelecido: O gênero feminino menos ativo que o masculino. As pessoas de 45 a 54 anos de idade são as mais ativas. Dos 18 a 24 anos estão as pessoas menos ativas. Os indivíduos que possuem o ensino fundamental incompleto são os mais ativos. Os que têm o ensino médio e superior completo são os menos ativos. Os mais ativos estão na faixa de renda superior a 6 salários mínimos. Os menos ativos são os com renda de até 2 salário mínimo. Motivações dos empreendedores estabelecidos "para fazer a diferença no mundo".

\section{Considerações Finais}

Após a análise dos dados foi possível alcançar o objetivo da pesquisa que foi analisar o perfil dos empreendedores iniciais e estabelecidos no Brasil e suas motivações, onde mostrou-se que as características e peculiaridades e a diversidade do empreendedor brasileiro, em aspectos etários, sociais e de gênero, a partir dos dados da GEM (2019), sobre os Perfil do empreendedorismo inicial e estabelecido e suas motivações iniciais. Os resultados apresentam os seguintes perfis:

a) Empreendedor em estágio inicial: Diferença mínima entre o gênero feminino e masculino. As pessoas com 25 a 44 anos de idade são os mais ativos. Encontram-se na faixa de 55 a 64 anos os menos ativos. Os indivíduos com o ensino superior completo são os mais ativos. As pessoas com o ensino fundamental incompleto são os menos ativos. As pessoas que estão na faixa de renda superior a 6 salários mínimos são as mais ativas. Os menos ativos estão na faixa de renda entre 1 até 2 salários mínimos.

b) Empreendedor em estágio estabelecido: $O$ gênero feminino menos ativo que o masculino. As pessoas de 45 a 54 anos de idade são as mais ativas. Dos 18 a 24 anos estão as pessoas menos ativas. Os indivíduos que possuem o ensino fundamental incompleto são os mais ativos. Os que tem o ensino médio e superior completo são os menos ativos. Os mais ativos estão na faixa de renda superior a 6 salários mínimos. Os menos ativos são os com renda de até 2 salários mínimos. 
c) Motivações dos empreendedores inicias: Em primeiro lugar, "Para ganhar a vida porque os empregos estão escassos" e em segundo "para fazer a diferença no mundo".

A contribuição desta pesquisa foi oferecer um panorama de informações recentes sobre empreendedorismo inicial e estabelecido, assim como as principais características de cada etapa e suas motivações dessa forma contribuindo para pesquisas futuras sobre o tema, trazendo as mais diversas reflexões para a sociedade. Como limitações desta pesquisa, tivemos a ampla amostragem que pode ser uma vantagem para a generalização, dessa forma uma desvantagem, dada à diversidade inclusa de neste banco de dados. Como sugestão desta temática para realizações de novas pesquisas, uso de amostra por segmentos para que se possa obter um maior conhecimento e entendimento acerca do empreendedorismo e dos seus agentes diversos.

\section{Referências}

Amorim, R. O., \& Batista, L. E. (2012). Empreendedorismo feminino razão do empreendimento. Núcleo de Pesquisa da FINAN, $3(3), 1-14$.

Arenhardt, R. L. (2019). Educação em empreendedorismo e sua relação com a intenção e a auto eficácia empreendedora em instituições de ensino superior brasileiras. 87 f. Tese (Doutorado) - Universidade Nove de Julho - UNINOVE, São Paulo.

Audretsch, D. (2012). Entrepreneurship research. Management Decision, 50, 755 - 764.

Ávila, L. V., Barros, I. C. F., Madruga, L. R. D. R. G., \& Júnior, V. F. S. (2014). Características das publicações sobre Empreendedorismo (Social) no Web of Science no período 2002-2011. Administração Pública e Gestão Social, 88-100.

Baggio, A. F., \& Baggio, D. K. (2015). Empreendedorismo: Conceitos e definições. Revista de empreendedorismo, inovação e tecnologia, 1(1), 25-38.

Baum, J. R., Frese, M., Baron, R. B., \& Katz, J. A. (2007). Entrepreneurship as an area of psychology study: an introduction. In J. R. Baum, M. Frese, \& R. B. Baron (Eds.), The psychology of Entrepreneurship (pp. 1-18). New Jersey: Lawrence Erlbaum Associates Inc. Publishers.

Bertolami, M., et al (2018). Sobrevivência de Empresas Nascentes: Influência do Capital Humano, Social, Práticas Gerenciais e Gênero. Revista de Administração Contemporânea, 22(3), 311-335. https://doi.org/10.1590/1982-7849rac2018160121

Cacciotti, G., Hayton, J. C., Mitchell, J. R., \& Giazitzoglu, A. (2016). A reconceptualization of fear of failure in entrepreneurship. Journal of Business Venturing, $31(3), 302-325$

Carrijo, Michelle \& Ferreira, Sara. (2017). Empreendedorismo Feminino No Brasil: Uma Análise A partir de Dados do Global Entrepreneurship Monitor (GEM). Rev. Empreendedorismo, Gestão e Negócios, 6(6).

Colauto, R. D., \& Beuren, I. M. (2006). Coleta, análise e interpretação dos dados. In. Beuren, I. M. (Org). Como elaborar trabalhos monográficos em contabilidade. (3a ed.), Atlas.

Cooley, L. (1990). Entrepreneurship training and the strengthening of entrepreneurial performance. USAID.

Dolabela, F. (2010). A corda e o sonho. Revista HSM Management, 80, 128-132.

Dornelas, J. C. A. (2007). Empreendedorismo na prática: mitos e verdades do empreendedor de sucesso. (2a ed.), Elsevier.

Dornelas, J. C. A. (2008). Empreendedorismo: transformando idéias em negócios. Elsevier.

Dornelas, J.; Timmons, J. A.; Spinelli, S. (2010). Criação de novos negócios: empreendedorismo para o século 21. São Paulo: Elsevier, Adaptação da $8^{\text {a }}$ edição americana.

Drucker, P. F. (1998). Inovação e espírito empreendedor: práticas e princípios. Pioneira.

Dutra, M. L. da S., et al. (2009). Empreendedorismo feminino: oportunidade ou necessidade? SEGET-XII -Simpósio de Excelência em Gestão e Tecnologia, Associação Educacional Dom Bosco.

Farber, S. G., Hoeltgebaum, M., \& Klemz, B. (2011). Cooperative Networks In Egepe Scientific Productions Of Studies On Entrepreneurship And Small Business Management. RAI, 8(3), 141.

Fillion, L. J. (1999). Diferenças entre sistemas gerenciais de empreendedores e operadores de pequenos negócios. Revista de Administração de Empresas, 39(4), 6- 20.

Franco, M. M. S. (2014). Empreendedorismo Feminino: Características Empreendedoras das Mulheres na Gestão das Micro e Pequenas Empresas. Goiânia: EGEPE.

Global Entrepreneurship Monitor - GEM. (2018). Empreendedorismo no Brasil: Relatório executivo. Curitiba: IBQP, 26. http://ibqp.org.br/PDF\%20GEM/Relat\%C3\%B3rio\%20Executivo\%20-\%20Brasil\%202018\%20-\%20web.pdf

Global Entrepreneurship Monitor - GEM. (2019). Empreendedorismo no Brasil: Relatório executivo. Curitiba: IBQP, 30 p. http://ibqp.org.br/PDF\%20GEM/Relat\%C3\%B3rio\%20Executivo\%20Empreendedorismo\%20no\%20Brasil\%202019.pdf 
Hisrich, R. D.; Peters, M. P.; Sheper, P. D. (2009). Empreendedorismo. (7a ed.), Artmed.

Hobsbawm, E. J. (2004). A era das revoluções 1789-1848. (18a ed.), Paz e Terra.

Kirzner, I. M. (1979). Perception, opportunity, and profit: studies in the theory of entrepreneurship. Chicago: University of Chicago Press.

Machado, Â. J. P., da Silva, C. R., \& Fernandes, Y. R. (2019). Perfil dos empreendedores brasileiros: o que mostra a pesquisa sebrae/ibpq/global entrepreneurship monitor. Administração 4.0: Flexibilidade para a Inovação das Organizações, 18.

McClelland, D. C. (1972). A sociedade competitiva. Expressão e Cultura

Nakao, A. N., da Costa Leite, L. E., \& da Cunha, J. A. C. (2018). Uma análise qualitativa da intenção empreendedora e do comportamento empreendedor no período de 2011 a 2015. REMIPE-Revista de Micro e Pequenas Empresas e Empreendedorismo da Fatec Osasco, 4(2), 271-295.

Neves, I. D., \& Amarante, J. M. (2020). De Empregado A Empregador: Compreensão das Trajetórias Empreendedoras de Ex-Funcionários de Empresas e TI Na Cidade De Maringá-Pr. Revista Livre de Sustentabilidade e Empreendedorismo, 5(4), 198-223. http://www.relise.eco.br/index.php/relise/article/view/403

Probst, E. R. (2005). A Evolução da mulher no mercado de trabalho. 2005.

Prodanov, C. C.; \& Freitas, C. C. (2013). Metodologia do trabalho científico: métodos e técnicas da pesquisa e do trabalho acadêmico. Novo Hamburgo: Universidade Feevale.

Raupp, F. M., \& Beuren, I. M. (2006). Metodologia da pesquisa aplicável às ciências sociais. In. Beuren, Ilse Maria. (Org). Como elaborar trabalhos monográficos em contabilidade. (3a ed.), Atlas.

Rocha, E. (2014). Oportunidade ou necessidade? um estudo do impacto do empreendedorismo no desenvolvimento econômico. Revista Gestão em Análise, 3(1/2), 31-46.doi:http://dx.doi.org/10.12662/2359-618xregea.v3i1/2.p31-46.2014

Scopelli, R. C., Galli, L. C. D. L. A., Louzada, R., Terence, A. C., \& Cassia, M. T. (2018). A Influência da Cultura Feminina no Comportamento Organizacional: Um Estudo de Caso Em Uma Organização Do Agronegócio. FACEF- Pesquisa-Desenvolvimento e Gestão, 20(1).

Schatz, S. P. (1971). On achievement and economic growth: a critical appraisal. In P. Kilby (Ed.), Entrepreneurship and economic development (pp. 183-190). New York: The free Press.

Schaefer, R., \& Minello, Í. F. (2019). Entrepreneurial education: entrepreneurial mindset and behavior in undergraduate students and professors. Revista de Negócios, 24(2), 61-90.

Schumpeter, J. A. (1997). Teoria do desenvolvimento econômico: uma investigação sobre lucros, capital, crédito, juro e ciclo econômico. Nova Cultural.

Serviço Brasileiro de Apoio às Micro e Pequenas Empresas - SEBRAE. (2019). Relatório especial: Empreendedorismo Feminino no Brasil. https://www.sebrae.com.br/Sebrae/Portal\%20Sebrae/UFs/GO/Sebrae\%20de\%20A\%20a\%20Z/Empreendedorismo\%20Feminino\%20no\%20Brasil\%202019_v 5.pdf

Serviço Brasileiro de Apoio às Micro e Pequenas Empresas - SEBRAE. (2020). Brasil deve atingir marca histórica de empreendedorismo em 2020. http://www.to.agenciasebrae.com.br/sites/asn/uf/TO/brasil-deve-atingir-marca-historica-de-empreendedorismo-em-2020,133b5f7a0ff92710Vg nVCM1000004c00210aRCRD

Silva Melo, M. R., \& de Jesus, D. L. N. (2018). Empreendedorismo feminino: desafios e oportunidades no cenário turístico de Campo Grande, Mato Grosso do Sul. Revista de Turismo Contemporâneo, 6(1).

Silva, J., \& Silva, M. (2019). Análise da evolução do empreendedorismo no brasil no período de 2002 a 2016. Revista Estudos e Pesquisas em Administração, 3(2), 115-137. https://doi.org/10.30781/repad.v3i2.8674

Vale, G. M. V., et al (2014). Motivações para o empreendedorismo: necessidade versus oportunidade? Revista de Administração Contemporânea, 18(3), 311327. https://doi.org/10.1590/1982-7849rac20141612

Woods, C. R. (2006). Asking the entrepreneur: An enquiry into entrepreneurial behaviour. Personal Construct Theory and Practice, 3(1), 1-11. http://www.pcpnet.org/journal/pctp06/woods06.pdf 